\title{
CLIMATE POLICIES: CHALLENGES, OBSTACLES AND TOOLS
}

\author{
Frederick van der Ploeg ${ }^{1,2,3,4_{\star}}$ \\ ${ }^{1}$ Department of Economics, University of Oxford, Oxford, United Kingdom \\ ${ }^{2}$ Faculty of Economics and Business, University of Amsterdam, Amsterdam, The Netherlands \\ ${ }^{3}$ Centre for Economic Policy Research (CEPR), London, United Kingdom \\ ${ }^{4} \mathrm{CESifo} \mathrm{GmbH}$, Munich, Germany \\ ${ }^{\star}$ Corresponding author. Email: rick.vanderploeg@economics.ox.ac.uk
}

A four-pronged approach to climate policy is presented consisting of carbon pricing, subsidies for renewable energies, transformative green investments and climate finance and engendering flywheel effects. Then, a variety of societal and political challenges and obstacles faced by such a climate policy and what can be done to overcome them are discussed. These range from stranded assets, the very long time scales needed to adapt and deal with global warming, intergenerational conflict, international free-rider problems, carbon leakage, green paradoxes, policy failure and capture, adverse income distributional effects and spatial scarcity to the problem of climate deniers and sceptics. The paper also discusses the various tools that are needed for the analysis of both ideal and workable climate policies, and the need to collaborate with complexity scholars, political scientists, sociologists and psychologists.

Keywords: carbon pricing; green investments; flywheel effects; leakage; green paradoxes; income distribution; political economy.

JEL codes: H23; Q54.

\section{Introduction}

The world is on course to higher temperatures unless emissions are brought down worldwide to zero. In the absence of an ambitious climate policy, temperature in the next 20 years will be 1.5 degrees Celsius higher than preindustrial temperatures compared with 1.1 degrees Celsius today. Such temperature increases will transform our planet. Many parts of the world will suffer from extreme temperatures, droughts, water shortages and desertification, and will become inhabitable. This will set in motion a colossal stream of climate migrants towards cooler areas of the globe and will incite conflict. Agricultural production will suffer until heat-resistant crops have been found. People will die earlier due to more days with extreme heat and respiratory illnesses. Higher global mean temperatures go together with more extreme weather events (flooding, hurricanes, wildfires and heat waves) as we are already seeing in many parts of the world. Lange et al. (2020) show that the occurrence of six categories of extreme events has already doubled but will increase fivefold by the time global mean temperature has risen to 2 degrees Celsius above preindustrial temperatures. To mitigate global warming, net emissions worldwide must be brought down to zero. A coordinated worldwide effort is to implement ambitious carbon pricing, renewable energy subsidies and climate finance, but until now the global community has failed miserably in this. Carbon pricing is very low and fragmented with very little coverage. International climate deals such as the Kyoto agreement have collapsed, and international climate treaties have run out of steam. At the same time, the world is addicted to fossil fuel with huge expenditures on fossil fuel subsidies and very little on renewable energy subsidies. It is therefore no surprise that, despite a dip during the corona pandemic, global carbon emissions and fossil fuel exploration are rising relentlessly. 
Still, financial markets, corporations, central banks and more and more governments are realising now that something must be done to stop the process of global warming for too much is at stake. In this paper, we first discuss in Section 2 a four-pronged approach to climate policy. We then discuss in Section 3 the numerous societal and political challenges and obstacles faced by such a climate policy and what can be done to overcome them. We then discuss in Section 4 the various tools that are needed for the analysis of both ideal and workable climate policies, and finally conclude in Section 5.

\section{Four-pronged approach to net-zero emissions}

Before we discuss various challenges and obstacles to a successful climate policy that ensures net-zero emissions, we state the four pillars of such a policy. These pillars are to announce a credible path of rising carbon prices either via carbon taxes or via tradable emission permits, have temporary hikes in renewable energy subsidies and transformative green investments, implement climate finance initiatives to overcome capital market failures faced by upcoming renewable energy companies and engender a whole range of flywheel effects in climate policy. We discuss each of these in turn below. We should also mention the need for adaptation to a changing climate. This would involve changing to heat-resistant crops, installing dikes and other flood-prevention measures, reorganising and rebuilding cities to cope with global warming and so forth. Most importantly, we should not forget no-brainers such as getting rid of all fossil fuel subsidies and having a moratorium on coal.

\subsection{Gradual carbon pricing: taxation and permit markets}

Most economists would favour pricing emissions of carbon, as this corrects the failure of markets to price the externalities imposed by emissions on other households and firms in the global economy. Greenhouse gases mix immediately, so it is important to have the same carbon price throughout the globe as has been argued by Chichilnisky and Heal (1994). This requires lump-sum transfers from rich to poor countries. Carbon pricing is ideally implemented via a global permit markets, since trading then leads to the most efficient cut in emissions. Firms that emit a lot with relatively less profits will sell their permits to firms that can make more profits per unit of emissions. Tradable permit markets automatically lead to uniform carbon pricing throughout the globe. Carbon pricing can also achieve this objective, but to get uniform carbon taxes in all countries, big transfers are needed from rich to poor countries.

Carbon pricing curbs demand for oil, gas and coal. Since coal is more carbon-intensive than oil or gas, its demand should fall by more if emissions are properly priced. It is less appreciated that carbon pricing has the added benefit of inducing substitution from carbon intensive fossil fuel (tar sands, coal and crude oil) to less carbon-intensive fossil fuel (gas), although that this does not mean that switching to gas is the answer to the climate challenge. It does help to give a temporary window of opportunity to switch to renewable energies. Carbon pricing, of course, also encourages substitution away from fossil fuel to renewables and brings forward the carbon-free era. Furthermore, carbon pricing makes it possible to set up a market for carbon capture and sequestration which would not lift off without an incentive for abating emissions. Similarly, carbon pricing would limit slash and burn of forests, which is important, as forests are an important absorber of carbon dioxide from the atmosphere and limit global warming in this way. Finally, carbon pricing makes it more attractive in the margin to perform research and development $(\mathrm{R} \& \mathrm{D})$ into clean fuel alternatives and into energy-saving technologies. Carbon pricing is preferable to subsidies, since the market knows better which options are better than the government.

There are two approaches to pricing carbon. The first one is to set the carbon price to the Pigouvian tax, which in climate economics is called the social cost of carbon (SCC). The second one is more pragmatic. It sets an upper limit on temperature or cumulative emissions and then derives the carbon price path that ensures that this target is met. This is the approach taken by the Intergovernmental Panel on Climate Change and the Network for Greening the Financial System (NGFS). We will discuss these in turn. 
The Pigouvian tax or SCC is the expected value of all the present and future damages from emitting 1 ton of carbon today. If all the other market failures and externalities are addressed, then setting this Pigouvian tax to the SCC is the welfare-maximising outcome. Since most integrated assessment models of the economy and climate assume that damages from global warming are proportional to output, the Pigouvian SCC is proportional to output too. The carbon price thus needs to rise at a rate equal to the nominal growth rate of the economy. The factor of proportionality is the product of the climate sensitivity to emissions and the marginal ratio of damages to output divided by the growth-and risk-adjusted discount rate. In the absence of uncertainty, this discount rate equals the rate of pure time preference plus the coefficient of intergenerational inequality aversion (IIA; i.e., the inverse of the elasticity of intertemporal substitution) times the real growth rate of the economy, according to the Keynes-Ramsey rule, minus the real growth of the economy to reflect that damage grow in line with the economy. Hence, the more impatient policymakers are the lower the discount rate and thus the higher the Pigouvian SCC. If trend growth is positive, future generations are richer, and thus this pushes up the discount rate and depresses the Pigouvian SCC provided IIA is greater than one, especially if IIA is large.

Under uncertainty, two additional terms need to be added to the discount rate. The first one is a negative one and reflects the prudence term which increases in the product of the coefficient of relative prudence $(1+$ IIA), the coefficient of relative risk aversion (RRA) and the volatility of asset returns and growth rate of the economy. This better-safe-than-sorry motive pushes up the Pigouvian SCC. The second one is positive and reflects the insurance term which increases in RRA and in the volatility of the economy. Since in future states of nature the growth rate of the economy and damages are perfectly correlated, policymakers can self-insure and thus employ a higher discount rate and thus set a lower Pigouvian SCC. An extensive discussion of these effects can be found in van den Bremer and van der Ploeg (2021) and the references cited therein. This study also allows for uncertainty about the temperature response and the damage ratio, which tend to boost the SCC especially if these uncertainties are high and skewed. A negative correlation between temperature or damage ratio shocks and the economy or asset returns implies a negative temperature beta and thus a higher Pigouvian SCC (provided RRA exceeds one). Others have emphasised the likelihood of climatic tipping points (e.g., melting of the Greenland or Antarctic Ice Sheet, melting of the permafrost or reversal of the Gulf Stream) being bigger at higher temperatures. Cai and Lontzek (2019) show that this substantially increases the optimal Pigouvian SCC.

The Pigouvian approach is what is taught to all economists but is not what has become popular among policymakers. A cap on temperature (e.g., 2 degrees Celsius or aiming for 1.5 degrees Celsius) or a cap on cumulative emissions has become the focal point for atmospheric and climate scientists as well as policymakers. One important reason for this is that scientists have recognised that temperature is driven by cumulative emissions, so a cap on temperature translates readily into a cap on cumulative emissions. A cap on cumulative emissions corresponding to a cap of 2 degrees Celsius, called the safe carbon budget, amounts to about 300 GtC (e.g., van der Ploeg, 2018), which corresponds to about 30 years if emissions remain at current levels. The market should be different between emitting today at the current carbon price and emitting in the future at the discounted value of the future carbon price. This arbitrage principle implies that the expected carbon price must grow at a rate equal to the riskadjusted real interest rate (i.e., a Hotelling rule). Here, the risk-adjusted interest rate equals the riskfree interest rate plus beta times the risk premium, where beta is found from regressing the log of marginal abatement cost on the growth of real consumption. This way of pricing carbon takes account of uncertain future marginal abatement costs and uncertain future size of the economy and emissions. Gollier (2017) finds that this principle suggests that carbon prices should grow in real terms at about 3.5 per cent per annum, which is a lot less than the 5-10 per cent per annum assumed by many integrated assessment studies or even the 15 per cent per annum used in some UK analyses. Using a too high growth rate for carbon prices inevitably leads to too little carbon pricing upfront, that is, to too much procrastination in climate policy. 


\subsection{Temporary hikes of renewable energy subsidies}

Global warming is not the only externality relevant for climate policy. Another important externality stems from Swanson's law, which states that every doubling of installed solar panels, windmills or batteries leads to a reduction of 20-30 per cent in the cost of each solar panel, windmill or battery. This law suggests the presence of strong learning-by-doing effects in the production of renewable energies. Each producer fails to internalise the future cost reductions that follow from producing one unit of renewable energy today. Just like the SCC, the social benefit of learning (SBL) is defined as the expected present discounted value of all present and future reductions in the cost of renewable energy resulting from producing and installing one unit of renewable energy today. The optimal climate policy then requires two policy instruments: a carbon price equal to the SCC and a renewable energy subsidy equal to the SBL. Following Goulder and Mathai (2000), Popp (2004), Edenhofer et al. (2005) and others, Rezai and van der Ploeg (2017a) use an integrated assessment model of the economy and the climate to show that this requires a combination of a gradual ramp in carbon prices and a temporary hike in renewable energy subsidies to speed up the transition to the carbon-free era. Acemoglu et al. (2012) point out that when there is directed technical change, a temporary renewable energy subsidy is needed alongside a carbon tax to shift the direction of technical progress radically from carbon-intensive to carbon-free means of production provided that substitution possibilities between carbon-intensive and carbon-free inputs are strong enough. Delay of implementation of the climate policy significantly increases the costs and may even push the economic-climate system beyond the point of no return.

\subsection{Transformative green investments and climate finance}

Governments should undertake large-scale, transformative green investment programmes. Globally, the International Monetary Fund calculated that this would amount to \$6-10 trillion (6-10 per cent of world GDP) with more than two-thirds coming from the private sector. The European Green Deal is a good example of this. Governments can act as launching customer in social housing, education and health sectors and redirect their investments in infrastructure to be green. For example, by designating certain cities or districts as green experiments, they can install heat pumps in new housing first and get households to use green electricity and other renewable energies instead of gas to heat the home and to cook. Such projects have demonstration value ('we can do it') and allow cities and districts to learn from each other, thus reducing costs over time. Another example is to temporarily subsidise households and companies to scrap their dirty vehicles and move to electrical vehicles, especially when a clear horizon is set from which only green modes of transport are permitted. Other examples of what is needed to radically shift to a green economy are smart electricity networks, energy efficiency measures, electrification of transports, buildings and industry, roll-out of electric vehicle charging stations and hydrogen factories.

Many renewable industries are new and struggling to get a foot in while companies based on fossil fuel have all kinds of incumbency advantages. One of the main problems is lack of good access to capital markets. Governments should step in and provide soft loans for such green companies. Another example of climate finance is catastrophic insurance bonds, which pay out when physical climate disasters strike. Monetary policy may also take account of transition risks and impose stricter liquidity constraints on firms and financial service companies that rely on fossil fuel and are subject to greater transition risk. At the Paris Summit (COP21) ratified in 2016, countries have agreed to take the lead in mobilising climate finance from a wide variety of sources, instruments and channels. This means local, national and transnational financing from public and private sources to enable mitigation and adaptation efforts. For example, the European Central Bank (ECB) has recently announced that it will green its quantitative easing programmes and take account of green considerations when purchasing green corporate bonds. But Papoutsi et al. (2021) have shown that the ECB until now has a brown bias in its corporate bond portfolio relative to a market portfolio of sectoral capital stocks, so it has some way to go. 


\subsection{Flywheel effects and policy, social and technological tipping points}

Pricing carbon, renewable energy subsidies and climate finance may not be enough to fully transition to a carbon-free economy. It is important to also consider flywheel effects that can be set in motion to get a cumulative dynamic in climate policy. One example is the idea of climate clubs advocated by Nordhaus (2015), which can lead to growing number of countries joining the climate club (see Section 3.4). This is an example of policy tipping: the more countries tip into action, the more other countries follow suit. Another example is technological tipping. For example, if demand for green technologies (e.g., solar panels, windmills, heat pumps or batteries) increases due to some intervention, then the scale of producing them increases and the cost drops, which then sets in motion a further increase in demand; and so forth. Cheap supply of green products only becomes available if there is enough demand, which calls for novel interventions. Radical figures in society can set in motion a shift towards greener preferences, which is a form of social tipping. All these tipping examples are driven by positive feedback effects.

Farmer et al. (2019) are inspired by complexity science where complex adaptive systems can cross critical thresholds (tipping points) to argue the case for exploiting sensitive intervention points. The idea is that a relatively small change can trigger a larger change that becomes irreversible, where nonlinear feedback effects act as amplifiers. The idea is thus to make use of amplification mechanisms in socioeconomic, technological and political systems to lead to a much more dynamic and increasingly more ambitious climate policy. This study discusses research and policies in which an intervention kicks or shifts the system, so that the initial change is amplified by feedback effects that deliver outsized impacts. The mechanisms to deliver such a kick might include network externalities, positive feedbacks (or strategic complementarities), self-fulfilling believing, sudden change in value and spreading of norms, learning curves and bandwagon effects. One example is that a radical and charismatic person can spark a revolution by demonstrating that their belief is more commonly held than they thought. Young (2015) discusses the evolution of social norms and the concept of punctuated equilibria and gives various examples such as the sudden change in the Chinese practice of foot binding. The key mechanisms setting in motion such amplification effects are positive feedback effects.

Otto et al. (2020) also give various examples of unleashing social and technological tipping points which unlock positive and rapid climate action and pave the way for rapid transformative change. This study points to a shift in moral norms or sudden breakthrough in renewable energy technology that leads to the end of fossil fuel. It also suggests concrete interventions which could trigger similar tipping points: getting rid of fossil fuel subsidies and incentivising renewable energy generation; building carbon-neutral cities; divesting from carbon-intensive assets; revealing the morally harmful nature of fossil fuels; strengthening climate education and engagement and building information feedback loops on greenhouse gas emissions. It is not always clear that all of these will engender positive feedbacks and amplification mechanisms, but it is worth investigating what interventions could do this.

Besley and Persson (2020) undertake a much more ambitious analytical exercise to analyse the interactions between business leaders, households and politicians. They highlight the socialisation of preferences arising from the notion that as more and more people are environmentalists, more materialists in society turn green. This strategic complementarity is also an example of positive feedback. By shifting resources, countries can shift from dirty to green directions of technologic progress. It also recognises that politicians cannot commit to future policies and that this together with the strategic complementarities can lead to a 'climate trap' where climate action does not come off the ground. They conclude that a grand coalition of visionary politicians, business leaders and people might shift a bad political-economic equilibrium to a better one where global warming is mitigated.

\section{Challenges and obstacles to successful climate policy}

Although the policies outlined in Section 2 might make sense to many economists, they are unlikely to be fully adopted by policymakers, as they give rise to many political and other obstacles. Economists need to 
get involved in the nitty gritty of second-best policymaking, which may not be ideal compared with policies that might be implemented without having to get a political majority for them. Hence, in this section, we briefly consider some of these political impediments such as stranded assets, the very long time scales needed, intergenerational conflict, international free-rider problems, carbon leakage, green paradoxes, policy failure and capture, adverse income distributional effects, spatial scarcity and the problem of climate deniers and sceptics. Some of these problems will be discussed in more and others in less detail.

\subsection{Risk of stranded carbon assets}

To keep global warming below 2 degrees Celsius, McGlade and Ekins (2015) have calculated using cost considerations and emission intensities that one-third of all oil reserves (but all of the Canadian tar sands and the Arctic oil and gas), half of all gas reserves and four-fifths of all coal reserves must be left unburnt. However, reserves found from the annual reports of oil, gas and coal companies suggest that global reserves are three times and the less probable reserves are 10-11 times the implied safe carbon budget (or cap on cumulative emissions). The Financial Times and others have argued for some time now that there is a Shakespearean moment with fossil producers facing their 'life or death' question. Investors fear increasingly that the growth in fossil fuel demand will not last forever with some predicting that in the next few years, there will be peak in demand, as climate policy tries to curb the use of fossil fuels and renewable energy is getting cheaper all the time. No chief executive of an oil company wants to be left holding multibillion-dollar oil fields the world no longer wants or needs.

There is thus a serious risk that oil, gas and coal reserves will have to be left in the crust of the earth, and that substantial exploration and exploitation investments must be written off. Furthermore, capital in carbon-intensive industries, such as cement or steel, but also in coal-fired power stations and transport (households as well as firms) face the risk of being stranded too. If this is the case, governments, if they have encouraged carbon-intensive investments in the past, may face litigation by firms that are at risk of stranded assets.

van der Ploeg and Rezai (2020) identify two conditions that must be fulfilled for assets to get stranded. First, there must be a previously unanticipated surprise intensification of climate policy, a sudden unexpected technological breakthrough in renewable energies leading to substantial cost reductions or a previously unanticipated shift in society towards greener preferences. Second, the investment must be irreversible or of the putty-clay variety, so that they cannot be quickly and cheaply redeployed in the upcoming renewable energy industries. With these two conditions satisfied, carbon-intensive capital must be scrapped and share prices of carbon-intensive firm will jump down. This study uses a dynamic general equilibrium framework to illustrate these effects including those of the risk of policy tipping. For example, the mere risk of a future stepping up of climate policy can lead to a race to burn the last ton of carbon when policymakers credibly employ a budget of cumulative emissions.

In practice, researchers have calculated by how much the economic lifetime of assets is shortened if the industry must meet its emissions reduction target. For example, Pfeiffer et al. (2017) use the concept of the 2 degrees Celsius capital shock to show that a 50 per cent probability of keeping temperature below 2 degrees Celsius cuts utilisation of coal-fired electricity generation in the period up to 2050 from 60 per cent to 29 per cent. Furthermore, no new emitting infrastructure can be built anymore unless older infrastructure is scrapped or fitted with carbon capture technologies.

The NGFS (a growing number of central banks) and financial regulators are seriously concerned about the risk of stranded assets and the systemic risks this imposes on the financial system. They clearly view it as part of their fiduciary responsibility. They are concerned about the physical as well as the transition risks faced by insurance companies. This is the reason why the ECB has greened their quantitative easing programmes. Central banks may also think about tightening the Basel ratios for carbon-intensive assets to limit risks of stranded assets. It is probably not a good idea to relax the Basel ratios for green assets as has been suggested by some commentators, as this carries the danger of increasing macroeconomic volatility. The NGFS is working towards a common framework for 
measuring carbon risks and conducting climate stress tests when policies are suddenly stepped up in the future to ensure that temperature does not rise above 1.5 or 2 degrees Celsius. This also helps to point to the countries and companies with most capital market exposure in the danger zone.

One could argue that the markets should be pricing in the transition risk, but there was little evidence for this until about 2015. Bolton and Kacperczyk (2021) find empirically that emissions affect returns of carbon-intensive firms in the United States positively from 2015 onwards even after controlling for the usual Fama-French factors (e.g., size, book to market and momentum). The interpretation is that investors have started to demand compensation for transition risk. This compensation is referred to as the carbon risk premium and cannot be explained by unexpected profitability or other risk premia. These results carry over to other countries too, and the carbon risk premium has been found to rise especially as awareness of the problem of global warming has increased. This is in stark contrast to those who argue the opposite and claim that going long on carbon-intensive firms and short on carbon-inefficient firms would generate abnormal positive returns. Delis et al. (2019) have found carbon risk premia in the corporate loan market from 2015 onwards too. Up to 2015, banks were not charging higher interest rates, but post 2015, banks did. Using an econometric model to explain interest spreads with a continuous indicator for fossil fuel exposure of each firm, they find that a 1 per cent increase in climate policy exposure and a 1 per cent increase in fossil fuel reserves imply a higher spread of, respectively, 16 and 7 basis points. Furthermore, they find that green banks charge fossil fuel firms much higher interest rates.

Now, markets seem to price in transition risk more and more, and the role of financial regulators may be less than when transition risk is not taken account of at all. However, since not all transition risk is priced in and reserves are many times bigger than the safe carbon budget, there is in my view still substantial systemic risk for financial markets and thus central banks and regulators are right to be concerned.

\subsection{Time scale and lack of hedging opportunities}

A big problem for policymakers is the huge time scales involved in climate policy. The risks of climate tipping points and damages occur already today but will happen with much increased intensity and frequency in the distant future. Climate risks thus occur very far in the future. Policymakers adopting the Pigouvian approach will not changes their actions much in response to these huge risks if they use the same discount rate to discount damages from 10 years in the future to the present as to discount from say 110 years to 100 years. Gollier (2017) and van der Ploeg (2020) review the various arguments why the discount rate should be declining in the horizon. One reason is that there is a constant but uncertain discount rate stemming from uncertainty about the drift or volatility of future consumption growth in which case the certainty-equivalent value of the discount rate to be used has a declining term structure. Another reason is autocorrelation in shocks to the rate of economic growth. Yet another reason is relative price effects resulting from different growth rates for ecosystem services and of labour in efficiency units. The point is that with a declining term structure, policymakers are more likely to undertake more vigorous climate policy. But almost no country has adopted a declining term structure for the social discount rate.

Another issue is that it is very difficult to find investment projects that yield a big return one or two centuries down the line if global warming turns out to be much more intense and harmful than expected. It is very difficult to imagine what such climate hedges could be other than adaptation efforts such as building dikes and flood defences and heat-resilient cities and agricultural systems.

\subsection{Big ask: intergenerational win-win outcomes}

Another political obstacle to successful climate policy is that current generations are asked to make sacrifices by paying more for their fossil fuel and carbon-intensive consumption commodities such as transport, heating and electricity in order to curb global warming many decades into the future. Without 
additional policies, future generations benefit at the expense of current generations. It is not difficult to see that this will be a hard sell politically. The answer to this policy challenge is for future generations to give transfers to current generations. This requires the government to run up government debt when implementing carbon pricing. Kotlikoff et al. (2021) use a detailed overlapping generations model with 55 generations, oil, coal and gas, and a climate module to search for generational win-win policies. They found that it is feasible to make all generations better off, but that this requires large transfers from future to current generations. By implementing their optimal carbon tax of 70 dollars per ton of carbon and letting it rise annually at 1.5 per cent per annum, the welfare of all generations rises uniformly by almost 5 per cent. Still, whether politicians are prepared to run up debt for such win-win situations is unclear even when all generations are in principle better off. Complementary intergenerational deals might be where current generations make sacrifices to fight global warming in return for better pay-as-you-go pensions, since this would lead future generations to also compensate current generations for their efforts to reduce future global warming.

\subsection{International free-rider issues, carbon leakage and border carbon tax adjustments}

If only a subset of countries, say the European countries, the United Kingdom, the United States, Canada and possibly China too, implement a gradually rising path of carbon prices, then carbon emissions in this subset of countries will fall, and thereby global mean temperature will fall or at least not rise as much. However, some of the incidence of carbon pricing is shifted from consumers and producers of final goods to producers of oil, gas and coal, especially if the supply of fossil fuel reacts strongly and demand reacts very little to the carbon price. This implies that prices of fossil fuel in those countries that do not price carbon or do not price carbon as much will fall, and thus demand for fossil fuel and carbon emissions in those countries will rise. Hence, the reduction in emissions in the subset of countries that price carbon is partially offset by the increase in emissions elsewhere. This phenomenon is called carbon leakage, and estimates vary widely from roughly 0 to 30 per cent. It illustrates the need to have a truly global climate deal where all countries commit to a common carbon price path.

Many countries especially if they are big producers of oil, gas and coal (e.g., the Gulf countries or Russia), or heavily dependent on fossil fuel and coal in particular (e.g., India and China), may not be willing to join such a global climate deal at this stage. Other countries that are in an earlier stage of development may not be able to afford to implement carbon pricing and thus may need transfers from developed countries. Despite more than three decades of international climate negotiations, such transfers have not been forthcoming at a big enough scale. ${ }^{1}$ For various reasons, the classic problem of international free-riding on climate policy is thus exacerbated by some countries unwilling to join a global climate deal, as this would destroy their economy if it relies on selling oil, gas and coal or this would harm their citizens whose main interest is to have shelter and food. The ethics is also complicated, since the biggest polluters in the past are today's rich industrialised countries and the bigger polluters of the present and the future are countries that are trying to catch up and develop.

In any case, the economics of international climate treaties suggest that coalitions that are both internally and externally stable (i.e., no country in the coalition is willing to leave and no country outside the coalition is willing to join) tend to be small. Barret (1994) suggests that the maximum coalition size is only three countries, but Karp and Simon (2013) show that this result is not robust, as it depends on specific linear-quadratic functional forms. Trigger strategies could sustain larger coalitions. de Zeeuw (2008) shows that farsightedness will sustain larger coalitions for one-shot games, but for dynamic games, this depends on the relative costs of abatement and emissions.

The best one can do in the absence of a sizeable climate coalition is to have a level playing field by levying a border tax adjustment, so that there is an additional carbon tax on all imported goods from

\footnotetext{
${ }^{1}$ Even if transfers are forthcoming, they would be financed from distorting taxes and would thus not lead to the efficient outcome for the global economy as pointed out by Chichilnisky and Heal (1994).
} 
countries that have no or lower carbon taxes. The European Union is moving in this direction, although industries such as steel and cement are not happy to give up their allocation of free permit allowances and crude measures must be used for emissions associated with each product. Fowlie and Reguant (2021) suggest second-best, industry-specific measures implying output-based rebates for industries that suffer most from carbon-intensive competition from abroad but still charge those industries the full carbon price on their emissions. These output-based rebates can substantially mitigate leakage, whereas the current practice of coarsely targeting subsidies on the basis of emissions intensities and trade exposure delivers only a bit of leakage while incurring significant costs.

The 1648 Treaty of Westphalia determined that nations are sovereign, have the right of selfdetermination, are legal and are free to manage their own affairs without intervention from other states. This means that participation by any nation in any climate agreement can only be voluntary. To overcome the resulting international free-riding problem and obtain a grand coalition of countries pursuing ambitious climate policies, Nordhaus (2015) has suggested that climate clubs with tariffs at the border might lead a growing size of the club. The idea is that those inside the club can trade freely with each other provided they all adhere to the agreed carbon pricing path, but countries outside the club who do not price carbon emission will face a tariff when they export any product to a country inside the climate club. Without the sanction of an external tariff, the climate club remains small with minimal abatement. With an external tariff of say 5 per cent, the climate club will grow with high levels of abatement. The point is that the larger the climate club becomes, the more attractive it becomes to trade with, and the more countries are willing to join the climate club.

\subsection{Political procrastination: green paradox effects}

Politicians tend to procrastinate and postpone unpopular policies, since they want to win elections and be popular. This leads to green paradox effects as first pointed out by Sinn (2008), and the consequent extensive literature is reviewed by van der Ploeg and Withagen (2015). The idea is that, if carbon pricing is postponed, producers of oil and gas anticipate that they will get less for their products in the future and thus accelerate oil and gas production by depleting faster. The mechanism is that oil and gas prices will fall in the anticipation period, thus boosting demand in this period, but oil and gas prices will rise once carbon prices have been implemented in the future and thus will depress future demand for oil and gas. This leads to an acceleration of global warming at least in the short run. The drop in current oil and gas prices and the carbon prices will curb incentives to explore and exploit new oil wells and gas fields, thereby locking more fossil fuel in the crust of the earth. This implies that less fossil fuel will be burnt in total, and total cumulative emissions of carbon and thus global mean temperature will decline in the long run. The net effect on welfare depends on whether the adverse effects of more global warming in the short run are outweighed by the beneficial effects of less global warming in the long run. The net effect is positive if the supply of oil and gas reserves is very sensitive to changes in oil and gas prices. In that case, green paradox effects will be modest.

Green paradox effects thus arise when carbon pricing is postponed, but also arise when policymakers prefer the carrot to the stick and shy away from carbon taxes in favour of excessive renewable energy subsidies. Despite a huge literature, it is my judgement that adverse green paradox effects are to be reckoned with but at the same time are at most a short-term inconvenience for a successful implementation of climate policy.

\subsection{Policy failure and capture of rents}

Other obstacles to successful climate policy are the lobbies from firms. Carbon-intensive firms that rely heavily on fossil fuel subsidies have in the past been successful in getting subsidies for their dirty modes of production. Indeed, total fossil fuel subsidies (including the cost of exemptions to carbon pricing) constitute 6-7 per cent of the global GDP, which is more than 40 times the budget for global renewable energy subsidies. Some of these subsidies, such as the ones for coal, are to ensure low electricity prices for 
the poor if electricity is produced using coal-fired power stations. Coal lobbies and populist interests keep these subsidies in place, even though a more efficient way to help the poor is to make the income tax system more egalitarian.

Carbon-intensive firms also lobby governments to be exempted from carbon pricing and lobby to have carbon pricing postponed. Some oil and gas firms are happy to have a carbon price if this price applies to coal as well as then they can expand the market for oil and gas. If coal-dependent firms must shut down after they have been encouraged to expand production by the government in the past, they will litigate and claim substantial sums of compensation. It may be easier to shut down and retire early very old coal-fired power stations as the United Kingdom has done, but this may be a less attractive option for countries with more modern coal-fired power stations with carbon capture and sequestration.

Renewable energy firms also lobby governments to get subsidies. If those subsidies internalise learning-by-doing externalities or are motivated by infant-industry arguments, this is fine. But if they are larger than that and persist too long, this can be a very costly alternative to carbon pricing. Governments shy away from carbon pricing and prefer subsidies, because it makes them more popular. But we have seen that this has the unintended consequence of green paradox effects. More generally, governments are very bad at picking winners of hitherto untested technologies and therefore a neutral policy such as carbon pricing is to be preferred to subsidies for specific technologies. Such specific renewable subsidies are prone to corruption and rent seeking by political friends. Furthermore, such subsidies are addictive and difficult to withdraw even when costs of say windmills or solar panels have fallen dramatically or when government have afterwards started to price carbon.

Nonprice controls such as energy efficiency standards, mandatory abatement and sequestration or renewable mandates are more susceptible to capture than carbon pricing. The hidden deadweight costs of such climate policy are not just the usual Harberger triangles but may also include the cost of rent seeking. Even efficient policies such as emission permit schemes are prone to lobbies. This can be seen from grandfathering permits, which implies that the biggest polluters (steel, cement, etc.) get handed out permits for free in proportion to their past pollution. This does not make sense, and as we have seen above, the efficient response is to subject all polluters to carbon pricing and to have a border tax adjustment to avoid carbon leakage (or have output-based rebates to mitigate carbon leakage).

Economists and policymakers are aware that it is efficient to have the same carbon price throughout the global economy, even though the world has failed miserably in achieving this. However, even within a particular country, the marginal cost of abating 1 ton of carbon varies hugely across industry and varies widely depending on the type of policy measure that has been used. Efficiency demands that for all policy measures and all sectors, the marginal cost of abatement is the same. This clearly is not the case in practice, since the bang per buck is much more for a carbon tax or roof insulation subsidy than for electrical cars in many countries. Furthermore, the subsidies for the different measures and sectors have income distributional consequences, and these must be taken account of. Hence, one would want to equalise the marginal cost abating 1 ton of carbon, properly corrected for the distributional impact (i.e., negative if it curbs income inequality and positive if it increases income inequality), for all possible measures and sectors. Governments are still a long way removed from doing this. It is therefore advisable to publish the full cost and distributional impact of each climate policy instrument, which is the first step towards a more efficient climate policy.

Finally, it is important to recognise that there is typically a hotchpotch of overlapping climate policies often in different jurisdictions which may lead to all kinds of inefficiencies (e.g., puncturing 'waterbed' effects). A good analytical discussion of when this will leverage additional climate benefits in the system and when not can be found in Perino et al. (2021).

\subsection{Carbon pricing hurts the poor relatively more}

Green tax reform is unpopular, because carbon pricing or the higher costs passed on to consumers by electricity and other producers of moving to green production hurt people in their pockets. Carbon 
pricing and such measures hurt the poor relatively most, as the budget shares of carbon-intensive consumption items, such as transport, heating and electricity, are higher for lower than for higher incomes. Carbon pricing is typically regressive. Pizer and Sexton (2019) review the distributional impacts of energy taxes and find that they may be less regressive than usually thought depending on the use of the energy tax revenues and the physical, social and climatic characteristics of the jurisdictions in which they are implemented. They also show that the variation in household energy expenditure is greater within income groups than across income groups and that it is not easy to curb such variation. Finally, the impact of carbon taxes on lifetime income is less regressive than on current income (e.g., Hassett et al., 2009; Rausch et al., 2011).

The Yellow Vests in France and other protest movements are directed at climate policies with a regressive impact. Hence, many have argued that carbon tax revenues should be rebated as visible, transparent lump-sum payments (climate dividends) to be paid to every citizen or household. Such carbon-tax-cum-dividend (CTCD) policies try to maximise fairness and the political viability of climate policy, since the climate dividend benefits the poor proportionally more, lowers inequality and offsets the regressive impact of carbon pricing. Horowitz et al. (2017) find that 70 per cent of people in the United States are better off if the revenue from taxing greenhouse gases at $\$ 49 / \mathrm{tCO}_{2}$ is rebated as an annual lump-sum dividend of $\$ 583$ per person. This suggests that CTCD policies might lead to a political majority. However, van der Ploeg et al. (2021) estimate a detailed commodity demand system and labour supply schedule for Germany and find that a CTCD policy does not make more than half the households better off. The reason is that the dividend makes people spend more and thus emissions are higher, while the adverse effect on labour supply of higher carbon prices is not mitigated. The CTCD policy is thus good for equity but bad for emissions and efficiency. In contrast, if the revenue of carbon taxes is recycled via lower income taxes instead of a dividend, the negative labour supply response is mitigated or even reversed. This way of recycling is thus good for efficiency, but bad for equity and even worse for emissions. The best way of recycling in terms of getting the biggest number of households that are better off (measured by equivalent variations) turns out to be a mix of handing out a climate dividend and lowering income taxes. To overcome the political obstacles to carbon pricing, one thus needs to carefully design a vote-winning mode of recycling.

Emissions data suggest that overall emissions increase with income, so that richer households have a larger carbon footprint. But emissions intensities fall with income. Hence, transferring one Euro from a poor to a rich household decreases overall emissions. This indicates that the trade-off between equity and efficiency might be a hard one. Recycling carbon tax revenue to the poor helps political acceptability of green tax reform, but Klenert et al. (2018) point out that other policies such as insulation subsidies for low incomes, subsidies for electrical vehicles or tax credits for energy-efficient buildings might sometimes be more appropriate.

\subsection{Spatial needs}

It should be recognised that rolling out renewable energy plants places a huge pressure on space. Windmills (if not in the sea), solar panels, hydrogen factories, batteries and carbon capture and sequestration must compete with roads, railways, dwellings, other factories and nature. Although a lot more can be done with smart design (solar panels on roofs, etc.), the spatial challenge is enormous especially in densely populated countries. The ugly face of not-in-my-backyard politics is already prominent as can be seen from protests from local people against new windmill parks and sequestration sites. Gates (2021) notes that the production of fossil fuel, nuclear energy, solar energy, hydropower, wind energy and wood and other biomass leads to, respectively, 500-1000, 500-1000, 5-20, 5-50, 1-2 and less than 1 Watt (Joule per second) of energy per square metre. Hence, producing fossil fuel or nuclear energy is a factor of couple of hundreds much more efficient in terms of space than renewable energies. Decarbonisation of the economy thus requires more pressure on space. Back-of-the-envelope calculations illustrate that densely populated countries such as the Netherlands cannot be self-sufficient 
in green energy ${ }^{2}$ and thus need to import a large amount from abroad once the economy has fully transitioned to be free of carbon. Of course, with smart design, these spatial demands can be reduced, but imports of green energy and the need to store it will be a huge future challenge. Along the way, there will be many people and businesses protesting against existing and new windmills and solar panels due to the space they require as well as due to health and other damages done to nature, thus frustrating the transition to a green economy.

\subsection{Climate deniers and sceptics}

Final big obstacles to a successful implementation of climate policy are climate deniers and climate sceptics. When such people have political power as in the United States under President Trump or in Poland or Brazil, they may be masquerading as climate deniers while in fact they are protecting vested coal interests. It is difficult to convince such climate deniers by atmospheric and climate science insights, especially as different false (and often morally questionable) and true narratives can co-exist as shown by Bénabou et al. (2018). Stating that climate policy is a hoax or a hobby for elites is an important cornerstone of modern-day populism. It works because it links up the interests of fossil fuel capitalists with low-income people often without a job in coal regions.

In principle, it may be possible to convince climate sceptics that something must be done to mitigate global warming. One could refer to the celebrated wager of Blaise Pascal, which argues that those who are sceptic about the existence of God do well to believe in God for the cost of not believing when God exists (hell) far outweigh the costs of believing when God does not exist (e.g., not swearing or not working on Sundays). However, small the probability that God exists, the payoff from believing always exceeds that from not believing. Atheists like climate deniers can never be convinced. But climate sceptics might be persuaded to be in favour of curbing global warming, since the welfare cost of conducting climate policy when the climate deniers are right are modest (e.g., relatively small Harberger triangles as the revenue from carbon pricing is recycled) and the welfare cost of not conducting climate policy when the climate scientists are right are potentially very large (e.g., a third of GDP with unfettered global warming leading to 4 or 5 degrees Celsius). Rezai and van der Ploeg (2017b) show that maximising welfare under the worst possible outcome or minimising the regret of conducting the wrong policy both lead to an ambitious climate policy. If a model uncertainty approach with ambiguity aversion is used, policymakers still pursue an aggressive carbon pricing policy even if a probability that climate deniers are right of 10 or 20 per cent is used.

\section{Tools for the analysis of climate policies}

The large-scale, detailed, multicountry integrated assessment models of the economic and climate systems have been used in many studies to calculate numerically the optimal carbon pricing and renewable subsidies necessary to internalise the current and future global warming damages to aggregate production for the global economy. These models have also been used to consider both noncooperative and cooperative climate policies but typically detailed submodels of international trade in goods and services or of international capital flows are lacking. They have also been used to study the impact on both intragenerational and intergenerational equity, but often these models do not include details on incomes and expenditures at the household level and do not use consumer expenditure surveys and income tax data. Furthermore, these models have been used to study what carbon pricing paths are necessary to achieve target emission reduction paths. However, despite the presence of a large and growing industry in integrated assessment models, they can be criticised. Their macroeconomic

\footnotetext{
${ }^{2}$ The fossil fuel production capacity of the Netherlands is 225 billion kWatt. In 2018, gas, wind energy and solar energy constitute 55, 13 and 11 per cent, respectively, of total energy production. If fossil fuel use is entirely replaced by domestic solar and wind energy production at an average of say 15 Watt per square metre, the additional space requirement for the Netherlands is roughly 15 million square kilometres. This is not available, as the Netherlands has a land area of only 41,542 square kilometres.
} 
structure is crude with many forward-looking elements in investment and consumption lacking. Their microfoundations are poor, and heterogenous agents are only allowed for in a rudimentary manner in these models. The dynamics of the distribution of income and wealth is typically not properly traced. These models can at best deal with some second-best issues (e.g., when only a subset of the necessary policy instruments can be used) but too often ignore other market failures such as lack of competition, capital market imperfections or lack of a full set of contingent insurance markets. The way these models deal with uncertainty about the economy, damages and temperature responses is rudimentary. At best, Monte Carlo simulations are used to assess best outcome under uncertainty, but these give very misleading results. These models also find it difficult to deal with regime shifts and multiple interacting climatic tipping points with the exception of Lemoine and Traeger (2016) or Cai and Lontzek (2019) who use a simplified version of the Dynamic Integrated Climate-Economy Model (DICE) integrated assessment model discussed by Nordhaus (2017).

The 1970s and early 1980s saw the end of large-scale, detailed Keynesian econometric forecasting models, which was prompted by the Lucas (1976) critique of econometric policy evaluation. ${ }^{3}$ Something similar may happen to the large-scale integrated assessment models of the economic and climate system that are now so widely used by various large modelling institutes and policymakers. There are various problems with such models. First, as already discussed, these models typically do not have forwardlooking behaviour as found in modern macroeconomics and lack serious microfoundations, have a coarse approach to heterogeneous households and firms, have rudimentary models of international trade and capital flows and lack political economy elements. Second, it may not be wise to have one supermodel for all questions. It may be better to have specific models to shed light on specific questions. For example, if countries face emissions reduction targets, detailed models of the small open economy are needed not necessarily large-scale global or multicountry models. Third, it is difficult to keep track of all the assumptions that are under the bonnet of these large-scale integrated assessment models. Individual team members know what they have done, but the rest of the model is too often like a 'black box' to them. Fourth, given that the models try to cover so much, it is an immense task to update the models regularly in the light of new data and insights. Fifth, the econometric evidence underlying these models is poor and often out of date. This is enough reason for Pindyck (2017) to dismiss using integrated assessment models altogether. He argues that these models create a perception of knowledge and precision that is illusory. He states that the effects of temperature on damages come out of thin air, and that integrated assessment models are close to useless for evaluating climate policy. Although there is truth in this, there is also new serious econometric research on a very detailed spatial level on the effects of temperature on GDP following the lead of Burke et al. (2015). This study obtains much higher (concave or linear instead of convex) effects of temperature on damages from those found in integrated assessment models.

To make progress, climate policy evaluation needs to become more empirically grounded and more micro-oriented. Different models may be needed to ask different sets of questions about climate policy. For example, one could use detailed models of specific countries or sectors of the economy to find the most efficient policies to ensure the target reduction in emissions while mitigating carbon leakage. One could use micro-econometric analysis to analyse and offset any adverse distributional and labour market impacts of carbon taxation. We could use microeconomic tools such as product-mix auctions or mechanism design to obtain the most efficient allocation of emission permits. One could apply frontier tools of applied economics such as randomised control trials, field and lab experiments, and discontinuity regression design to obtain detailed sound econometric estimates of the effects of global warming and extreme weather events on communities at a very granular level. One could collaborate with the best macroeconomic and finance scholars to obtain a more satisfactory treatment of risk and uncertainty, and study how transition risk and physical risks affect asset prices and the risk of stranded assets. This can

\footnotetext{
${ }^{3}$ Any apparent trade-off between inflation and unemployment would disappear as soon as policy makers try to exploit it by, say, buying extra jobs at the expense of a bit of extra inflation. Wage setters with rational expectations would immediately see such tactics and would revise their expectations of price inflation, thus nullifying any effect on aggregate demand and jobs.
} 
also lead to deeper insights into green multipliers and the use of government debt to obtain intergenerational win-win situations. Collaboration with development scholars can help to come up with better solutions for sustainable development. Economists can work with political scientists to better understand the political situation under which climate policy has to be conducted and come up with workable climate policies that can count on a political majority and have a more realistic chance of being adopted. Finally, economists should gain from the insights of sociologists and psychologists to understand changing preferences, social tipping points and flywheel effects in climate policy.

\section{Conclusion}

From a policy point of view, governments should get rid of explicit and implicit fossil fuel subsidies, have a moratorium on coal production, put a firm date after which diesel- and petrol-based transport is no longer permitted, give a clear signal by announcing a credible path of rising carbon prices, give subsidies for renewable industries that are subject to learning-by-doing and infant industry effects, make capital available for renewable energy firms with insufficient access to capital markets and include the new additional demand for renewable energies in careful spatial planning. Government could lead the way by investing in clean infrastructure, efficient retrofitting of buildings and green R\&D. Governments should not waste time or succumb to lobbies, since this will make realising the climate targets only more costly. Instead, firms should become carbon-free and ensure that one way or another they capture and sequester all carbon emissions. This is the way to transition to a net-zero economy, where any remaining positive emissions are fully offset by capture and sequestration. After the Corona-19 pandemic, it is essential to build back better and greener including investments in control of the pandemic (test, track and contain), vaccines, border checks, safe travel and food, shorter local supply chains and secure networks. The objective is to make sure that all jobs and sectors of the economy are green and corona-proof, thus making our economies more resilient. At the same time, politicians should listen to the new green industries and not succumb to the pressures of fossil fuel incumbents who might try to frustrate plans to make our society greener and more resilient. Zombie firms from the fossil fuel era should not be kept alive unless they transform to carbon-free enterprises. As Henderson (2021) has argued, to tackle the triple crisis of the collapse of the environment, increase in inequality and collapse of institutions and threat to democracy, society needs to encourage purpose-driven firms and innovation and to rebuild institutions and bring markets and government back in balance. Mazzucato (2021) is right that most successful inventions have their roots in government-sponsored research, so that new ventures between the government and the private sector is needed. The extraordinary achievement of getting various effects vaccines against Corona-19 in less than a year has followed this pattern. Similarly, a worldwide, large-scale public-private effort is needed to find new cost-effective ways to transition the global economy out of fossil fuel into renewable energies.

Acknowledgements. This paper is a write-up of a presentation of a keynote lecture given at the 17th EUROFRAME Conference on Economic Policy Issues in the European Union, NIESR, London, on 17 June 2021. I am grateful to my friend and co-author Armon Rezai for many useful and inspiring discussions on the topic of this keynote and to an anonymous referee for helpful suggestions for improvement.

\section{References}

Acemoglu, D., Aghion, P., Bursztyn, L. and Hemous, D. (2012), 'The environment and directed technical change', American Economic Review, 102, 1, pp. 131-66.

Barret, S. (1994), 'Self-enforcing international environmental agreements', Oxford Economic Papers, 46, pp. 878-94.

Bénabou, R., Falk, A. and Tirole, J. (2018), 'Narratives, imperatives, and moral reasoning', Working paper 24798, National Bureau of Economic Research, Cambridge, Massachusetts.

Besley, T. and Persson, T. (2020), 'Escaping the climate trap? Values, technologies, and politics', Mimeo, London School of Economics and Political Science, London, United Kingdom. 
Bolton, P. and Kacperczyk, M.T. (2021), 'Do investors care about carbon risk?', Journal of Financial Economics, forthcoming.

Burke, M., Hsiang, S.M. and Miguel, E. (2015), 'Global non-linear effect of temperature on economic production', Nature, 527, pp. 235-9.

Cai, Y. and Lontzek, T.S. (2019), 'The social cost of carbon with economic and climatic risks', Journal of Political Economy, 127, 6, pp. 2684-734.

Chichilnisky, G. and Heal, G. (1994), 'Who should abate carbon emissions? An international perspective', Economics Letters, 44, pp. 443-9.

de Zeeuw, A.J. (2008), 'Dynamic effects on the stability of international environmental agreements', Journal of Environmental Economics and Management, 55, pp. 163-74.

Delis, M.D., de Greiff, K. and Ongena, S. (2019), 'Being stranded on the carbon bubble? Climate policy risk and the pricing of bank loans', Swiss Finance Institute Research Paper Series No 18-10, Swiss Finance Institute, Geneva, Switzerland.

Edenhofer, E., Bauer, N. and Kriegler, E. (2005), 'The impact of technical change on climate protection and welfare: Insights from the model MIND', Ecological Economics, 54, pp. 277-92.

Farmer, D., Hepburn, C., Ives, M.C., Hale, T., Wetzer, T., Mealy, P., Rafaty, R., Srivastav, S. and Way, R. (2019), 'Sensitive intervention points in the post-carbon transition', Science, 364, 6436, pp. 132-4.

Fowlie, M. and M. Reguant (2021), 'Mitigating emissions leakage in incomplete carbon markers', Journal of the Association of Environmental and Resource Economists, forthcoming.

Gates, B. (2021), How to Avoid a Climate Disaster: The Solutions We Have and the Breakthroughs We Need, London: Penguin Books.

Gollier, C. (2017), Ethical Asset Valuation and the Good Society, New York: Columbia University Press.

Goulder, L. and Mathai, K. (2000), 'Optimal $\mathrm{CO}_{2}$ abatement in the presence of induced technical change', Journal of Environmental Economics and Management, 39, pp. 1-38.

Hassett, K.A., Mathur, A. and Metcalf, G.E. (2009), 'The incidence of a U.S. carbon tax: A lifetime and regional analysis', The Energy Journal, 30, 2, pp. 155-78.

Henderson, R. (2021), Reimagining Capitalism in a World on Fire, London: Penguin Business.

Horowitz, J., Cronin, J.-A., Hawkins, H., Konda, L. and Yuskavage, A. (2017), 'Methodology for analyzing a carbon tax', Office of Tax Analysis Working Paper 115, U.S. Department of the Treasury, Washington, DC.

Karp, L. and Simon, L. (2013), 'Participation games and international environmental agreements: A non-parametric model', Journal of Environmental Economics and Management, 65, 2, pp. 326-44.

Klenert, D., Mattauch, L., Combet, E., Edenhofer, O., Hepburn, C., Rafaty, R. and Stern, N. (2018), 'Making carbon pricing work for citizens', Nature Climate Change, 8, pp. 669-77.

Kotlikoff, L., Kubler, F., Polbin, A., Sachs, J. and Scheidegger, S. (2021), 'Making carbon taxation a generational win win', International Economic Review, 62, 1, pp. 3-46.

Lange, S., Volkholz, J., Geiger, T., Zhao, F. et al. (2020), 'Projecting exposure to extreme climate impact events across six event categories and three spatial scales', Earth's Future, 8, 12, p. e2020EF001616.

Lemoine, D. and Traeger, C.P. (2016), 'Economics of tipping the climate dominoes', Nature Climate Change, 6, pp. 514-9.

Lucas, R.E. (1976), 'Econometric policy evaluation: A critique', in Brunner, K. and Metzler, A. (eds), The Phillips Curve and Labor Markets, Carnegie-Rochester Conference Series on Public Policy, Volume 1, New York: Elsevier, pp. 19-46.

Mazzucato, M. (2021), Mission Economy. A Moonshot Guide to Changing Capitalism, London: Allen Lane, Penguin Random House.

McGlade, C. and Ekins, P. (2015), 'The geographical distribution of fossil fuel unused when limiting global warming to $2^{\circ} \mathrm{C}$ ', Nature, 517, pp. 187-90.

Nordhaus, W. (2015), 'Climate clubs: Overcoming free-riding in international climate policy', American Economic Review, 105, 4, pp. 1339-70.

Nordhaus, W. (2017), 'Revisiting the social cost of carbon', Proceedings of the National Academy of Sciences of the United States of America, 114, 7, pp. 1518-23.

Otto, I.M., Donges, J.F., Cremades, R., Bhowmik, A. et al. (2020), 'Social tipping dynamics for stabilizing Earth's climate by 2050', Proceedings of the National Academy of Sciences of the United States of America, 117, 5, pp. $2354-65$.

Papoutsi, M., Piazzesi, M. and Schneider, M. (2021), 'How unconventional is green monetary policy?' Mimeo, Stanford University, Stanford, California.

Perino, G., Ritz, R.A. and van Benthem, A.A. (2021), 'Overlapping climate policies', Mimeo, University of Pennsylvania, Philadelphia, Pennsylvania.

Pfeiffer, A., Millar, R., Hepburn, C. and Beinhocker, E. (2017), 'The " $2{ }^{\circ} \mathrm{C}$ capital stock" for electricity generation: Committed cumulative carbon emissions from the electricity generation sector and the transition to a green economy', Applied Energy, 179, pp. 1395-408.

Pindyck, R. (2017), 'The use and misuse of models for climate change', Review of Environmental Economics and Policy, 11, 1, pp. 100-14.

Pizer, W.A. and Sexton, S. (2019), 'The distributional impacts of energy taxes', Review of Environmental Economics and Policy, 13, 1, pp. 104-23. 
Popp, D. (2004), 'ENTICE: Endogenous technical change in the DICE model of global warming', Journal of Environmental Economics and Management, 48, pp. 742-68.

Rausch, S., Metcalf, G.E. and Reilly, J.M. (2011), 'Distributional impacts of carbon pricing: A general equilibrium approach with micro-data for households', Energy Economics, 33, 3, pp. S20-33.

Rezai, A. and van der Ploeg, F. (2017a), 'Abandoning fossil fuel: How fast and how much', Manchester School, 85, S2, e16-44.

Rezai, A. and van der Ploeg, F. (2017b), 'Climate policies under climate model uncertainty: Max-min and min-max regret', Energy Economics, 68, pp. 4-16.

Sinn, H.W. (2008), 'Public policies against global warming', International Tax and Public Finance, 15, 4, pp. 360-94.

van den Bremer, T.S. and van der Ploeg, F. (2021), 'The risk-adjusted carbon price', American Economic Review, 111, 9, pp. 2782-810.

van der Ploeg, F. (2018), 'The safe carbon budget', Climatic Change, 147, pp. 47-59.

van der Ploeg, F. (2020), 'Discounting and climate policy', Oxford Research Encyclopedia Economics and Finance, available online at https:/oxfordre.com/economics/view/10.1093/acrefore/9780190625979.001.0001/acrefore-9780190625979-e-581.

van der Ploeg, F. and Rezai, A. (2020), 'The risk of policy tipping and stranded carbon assets', Journal of Environmental Economics and Management, 100, p. 102258.

van der Ploeg, F., Rezai, A. and van der Ploeg, F. (2021), 'Gathering political support for green tax reform: Surprising evidence from German household surveys', Mimeo, Department of Economics, University of Oxford, Oxford, United Kingdom.

van der Ploeg, F. and Withagen, C. (2015), 'Global warming and the green paradox: Review of the adverse effects of climate policy', Review of Environmental Economics and Policy, 9, 2, pp. 285-303.

Young, P. (2015), 'The evolution of social norms', Annual Review of Economics, 7, pp. 359-87.

Cite this article: van der Ploeg, F. (2021), 'Climate policies: Challenges, obstacles and tools', National Institute Economic Review, 258, pp. 12-27. https://doi.org/10.1017/nie.2021.29 